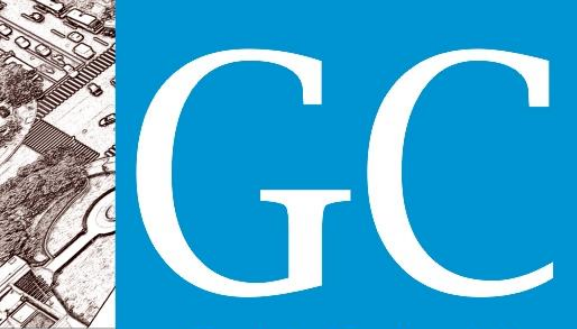

Revista Nacional de

Gerenciamento de Cidades

\title{
Transformações urbanas em Baku no século XXI
}

Baku's urban transformation in the 21th Century

Transformación urbana de Baku nel siglo XXI

Maria Isabel Imbronito

Professora Doutora, USJT, Brasil

imbronito@gmail.com

Danilo Firbida de Paula

Mestrando, USJT, Brasil

df.arquiteto@gmail.com 


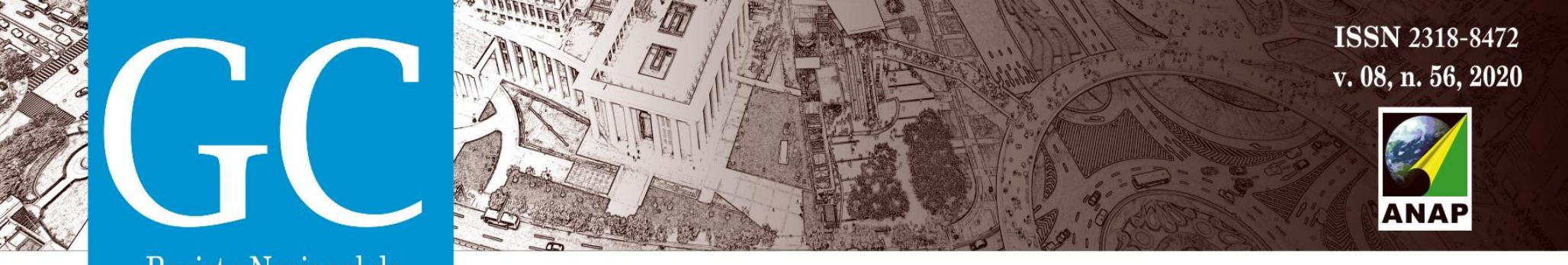

\section{Revista Nacional de \\ Gerenciamento de Cidades}

\section{RESUMO}

Este trabalho pretende fornecer elementos para o entendimento das transformações urbanas recentes de Baku, capital do Azerbaijão, apoiando-se nas circunstâncias históricas e atuais do Azerbaijão, e no mapeamento das intervenções, organizadas de modo a traçar sobre a cidade arcos de desenvolvimento urbano que foram identificados na pesquisa.

PALAVRAS-CHAVE: Cidade global. Urbanismo do século XXI. Projeto urbano.

\section{ABSTRACT}

This paper aims to provide elements for the comprehension of the urban transformations in Baku, capital of Azerbaijan, relying on the historical and current circumstances of Azerbaijan and on the interventions which configure urban development arcs that were identified in our research.

KEY WORDS: Global city. 21 $21^{\text {st }}$ century urbanism. Urban design.

\section{RESUMEN}

Este trabajo pretende proporcionar elementos para el entendimiento de las transformaciones urbanas de Bakú, capital de Azerbaiyán, apoyándose en las circunstancias históricas y actuales de Azerbaiyán y en el elenco de las intervenciones y los arcos de desarrollo urbano que fueron identificados en esta investigación.

PALABRAS CLAVE: Ciudad global. Urbanismo del siglo XXI. Proyecto urbano. 


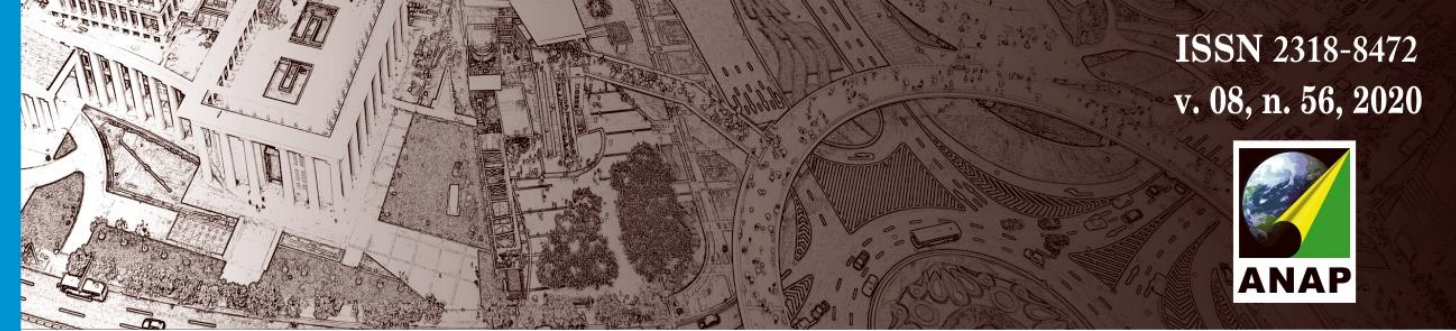

Revista Nacional de

Gerenciamento de Cidades

\section{TRANSFORMAÇÕES URBANAS DE BAKU NO SÉCULO XXI}

\section{INTRODUÇÃO}

Este texto tem três propósitos: fazer um mapeamento dos empreendimentos recentes na cidade de Baku, capital do Azerbaijão, inserindo-as num plano geral da cidade; buscar elementos conjunturais que forneçam a contextualização do fenômeno observado em Baku; discutir o fenômeno observado a partir de bibliografia selecionada, o fenômeno observado.

Para tanto, foi feita uma revisão das prerrogativas históricas, políticas e econômicas capazes de explicar a transição do Azerbaijão, país de economia com base no petróleo, rumo a uma inserção global a partir de 1991, no momento em que ocorreu a autonomia política do país. Para tanto, considera-se importante compreender que o território que corresponde hoje ao Azerbaijão apenas recentemente surgiu como país independente. Segue-se uma revisão bibliográfica que estabelece uma reflexão sobre o urbanismo recente, pautado em ações de valorização do contexto histórico e local sob articulações urbanas que geram grandes negócios, reforçando as motivações comerciais de grandes operações urbanas. Na sequência, é proposta uma leitura espacial da cidade baseada na localização dos novos empreendimentos que, ao serem inseridos em uma base cartográfica, revelam a concentração ao longo de dois diferentes vetores de transformação: o primeiro ligado à orla do Mar Cáspio, e o segundo, paralelo ao primeiro, conectando as obras do distrito de Sovetsky e Winter Boulevard até a Avenida Heydar Aliyev.

Devido à atualidade dos fatos, o levantamento das intervenções e obras de arquitetura recentes está apoiado em fontes da internet: sites dos escritórios envolvidos nos projetos, sites oficiais do governo e matérias diversas sobre as obras. Foi também de fundamental importância uma visita a campo realizada a Baku em janeiro de 2017. A visita, juntamente com estudos sobre a cartografia da cidade, foi definidora na identificação dos dois eixos de desenvolvimento e dos diferentes setores que os compõem. Os setores foram definidos no andamento da pesquisa, adotando-se critérios de localização, afinidade tipológica ou funcional, e são conectados entre si por linhas de mobilidade ou pela própria conformação territorial, em proximidade uns com os outros. Do ponto de vista de sua genealogia, os setores mapeados podem apresentar origem histórica ou resultar do processo de transformação recente. Para a completa articulação entre os setores, áreas consolidadas da cidade foram compreendidas como partes ativas no novo agenciamento urbano. Por outro lado, áreas inteiras passaram por transformações súbitas, que se sobrepuseram inteiramente às antigas ocupações, fenômeno que adequa-se ao conceito que Solà-Morales denominou "Mutação" (2002, p.85), caracterizado por transformações súbitas em grande escala que se sobrepõem ao processo de transformação lento e evolutivo de formação das cidades, mas que, em sintonia com o acúmulo de meios públicos e privados e tecnologias de destruição e construção rápidas, resultam em alterações abruptas de grande extensão nas cidades. Para o autor, as Mutações são processos autônomos, autorreferentes, que estabelecem lógicas novas e de pouca relação com as bordas exteriores do entorno existente. 


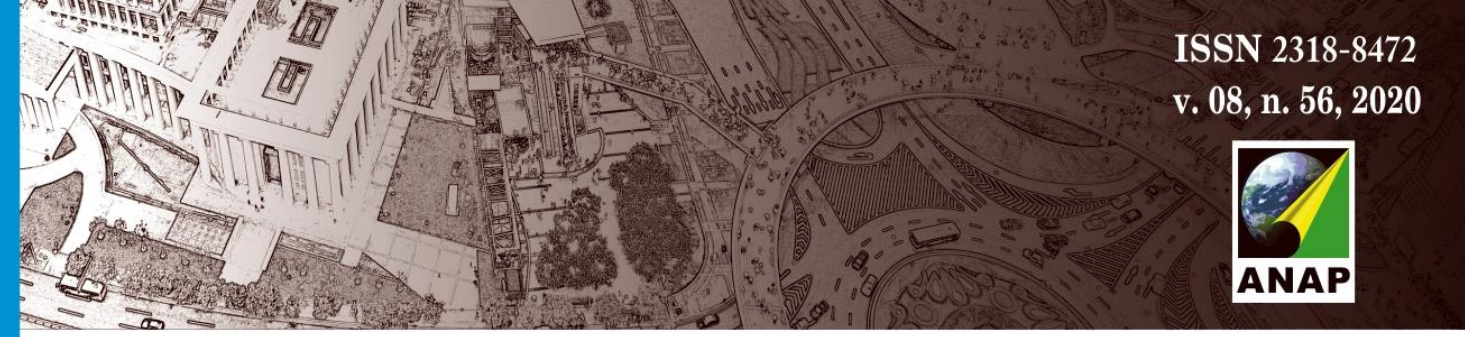

\section{Revista Nacional de}

Gerenciamento de Cidades

La capacidade de acumular poderosos médios públicos y privados y las tecnologias de destruicción rápida y de no menos rápida nueva edificación, hacen que centenares de hectares de ciudades ya existentes, o de espacios hasta ahora no urbanos, sufran verdadeiras mutaciones, súbitas, casuales e imprevisibles desde la lenta lógica de la evolución. (SOLÀ-MORALES, 2002, p.85).

FIGURA 1: Azerbaijão, em vermelho na planificação.

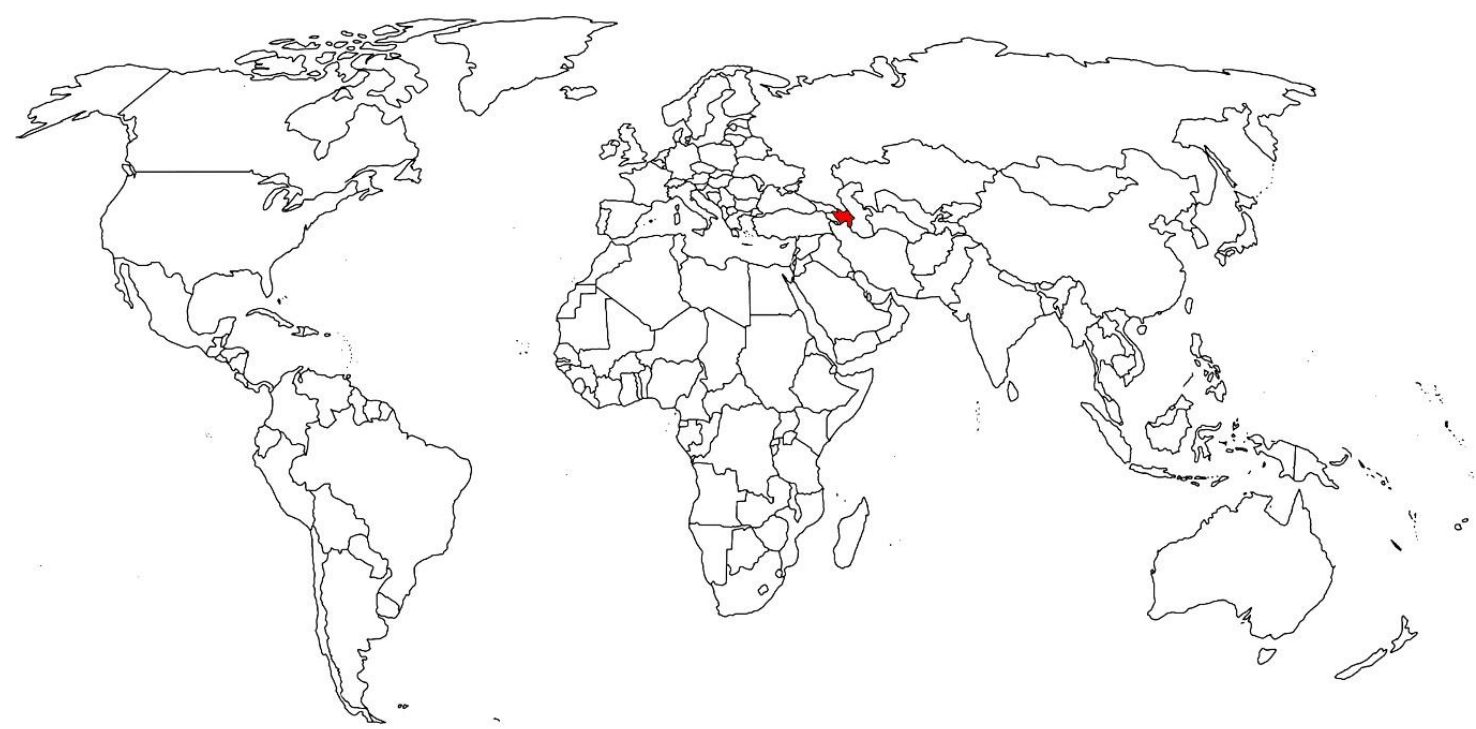

FONTE: Produzido pelos autores, a partir de mapa mundi disponível em Estados e Capitais do Brasil.com.

\section{CONSTRUÇÃO HISTÓRICA ATÉ O PRESENTE}

O atual território do Azerbaijão foi parte constituinte de diversos impérios no decorrer dos séculos compondo áreas no limite da expansão de poderosas forças políticas e bélicas que se sucederam em processos de apogeu e queda. Em decorrência destes processos sucessivos e de sua posição de fronteira, as delimitações territoriais, a composição étnica, as inclinações religiosas ou culturais e a representação política desta região não foram sempre coincidentes, fato que marca a história e caracteriza o povo azeri.

Esta região do Cáucaso já era parte do Primeiro Império Persa por volta do ano 600 a.C., e compõe o território persa até o último império pré-islãmico, no século VII d.C. Segundo WALL (2010, p.22), o processo de unificação religiosa árabe em torno de Maomé e a expansão territorial dos califados árabes nos séculos VIII ao X sedimentou a religião islâmica no sudeste do Cáucaso, atual Azerbaijão, enquanto que, nas áreas vizinhas ao norte e a oeste, as ocupações judaica e cristã detiveram o avanço islâmico nos territórios hoje pertencentes a Geórgia, Armênia e Rússia. 


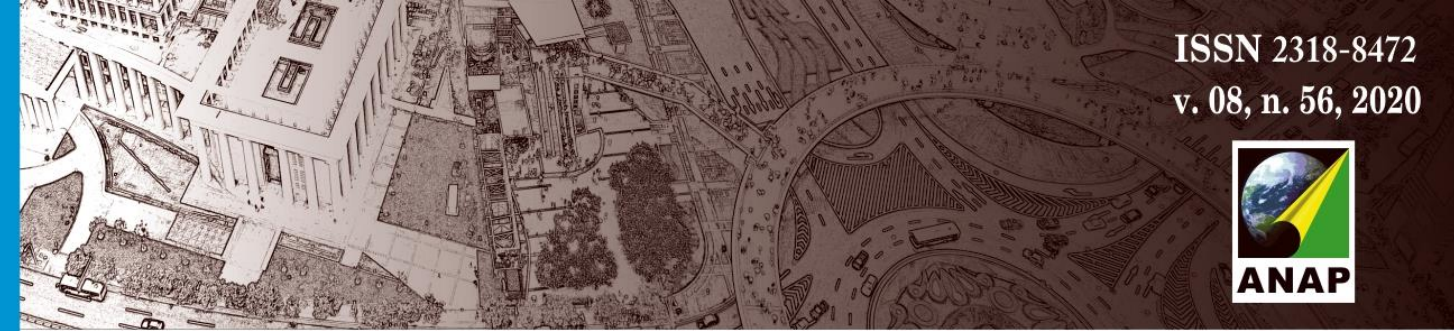

Revista Nacional de

Gerenciamento de Cidades

Após o declínio da expansão árabe, na Alta Idade Média a região pertenceu ao Império Corasmo Turcomano. Durante o século XIII, sedimentam-se as principais características culturais e constituidoras do povo (CURTIS, 1995, p.88). A região foi, ainda no século XIII, invadida pelo Império Mongol. Integrou parte deste último ao final do século XIII, pertencendo a uma de suas frações conhecida como Ilcanato. No século XIV, ainda sob domínio mongol, implantou-se a dinastia Shirvan, cujo palácio sobrevive até hoje na parte medieval de Baku (CURTIS, 1995, p.89). Em 1501, a dinastia Safávida tomou o poder na região, e constituiu um novo império persa por cerca de 200 anos. Ao fim, seu território foi cedido a pressões de turcos e russos (CURTIS, 1995, p.89).

A região do Azerbaijão foi parte do grande Império Turco-Otomano do século XVIII até meados do século XIX, quando foi incorporada ao Império Russo Czarista na passagem conhecida como Guerra do Cáucaso. Foi no período de domínio da Rússia Imperial que a extração de petróleo no Azerbaijão, conhecida desde a Idade Média, foi ampliada e modernizada. Data de 1880 a disseminação do termo Black Town (Cidade Preta) para o setor industrial de Baku, devido aos campos de extração em solo (WALL, 2010, p.167). Sob domínio russo, com o desenvolvimento da indústria do petróleo, a população da cidade aumentou cerca de 15 vezes em quarenta anos ${ }^{1}$. Com a presença de muitos russos em Baku, ampliou-se a influência cultural russa. Os russos eram responsáveis pela extração do petróleo, mas os azeris enriqueceram devido ao transporte por terra e por mar (CURTIS, 1995, p.90).

O Azerbaijão esteve sob domínio russo até a dissolução do Império com a revolução de 1917, e teve uma brevíssima existência, entre 1918 e 1920, como estado independente, a República Democrática do Azerbaijão, proclamada por nacionalistas muçulmanos. Foi, em 1922, incorporado à União das Repúblicas Socialistas Soviéticas, inicialmente como parte de uma divisão que integrava os países do Cáucaso (a República Federativa Transcaucasiana, que juntava Armênia Geórgia e Azerbaijão), e depois como República Socialista Soviética do Azerbaijão, em 1936, para permanecer no bloco até sua dissolução, em 1991.

No período soviético, destaca-se o interesse alemão pelo petróleo do Azerbaijão durante a Segunda Guerra Mundial, cuja invasão não chegou a termo, mas, juntamente com a exaustão dos campos de extração em solo, deslocou o foco soviético para a produção nos Urais, causando desaceleração no território do Azerbaijão (WALL, 2010, p.168). Após a guerra, surgiram as primeiras iniciativas soviéticas para extrair petróleo de poços do mar Cáspio, que culminou com a construção, em 1949, de Oil Rocks, cidade-plataforma sobre as águas do período stalinista (WALL, 2010, p.170).

No regime soviético, notam-se distintos graus de autoridade de Moscou sobre as Repúblicas, alternando-se períodos mais ou menos repressivos. Sob o estado ateu, a religião islâmica foi desencorajada e quase a totalidade das mesquitas em Baku foi destruída. As poucas que restaram foram compartilhadas entre sunitas e xiitas, o que, de certo modo, pode ser

\footnotetext{
${ }^{1}$ Em 1860, Baku tinha 13.000 habitantes; em 1897, 112.000 habitantes; em 1913, 215.000 habitantes, tornando-se a maior cidade do Cáucaso. Dados extraídos de CURTIS (1995, p.90).
} 


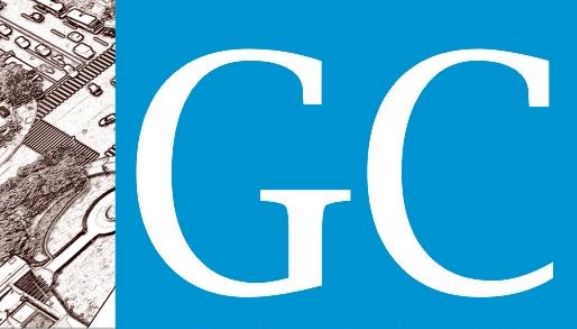

\section{Revista Nacional de}

Gerenciamento de Cidades

relacionado ao movimento pan-islâmico que se percebe no Azerbaijão (WALL, 2010, p.23). Também explica porque, em Baku, grande parte das mesquitas são recém-construídas, conforme constatou-se em visita a Baku.

Figura 2: 0 território pertencente ao atual Azerbaijão como parte constituinte de diversos impérios ao longo do tempo.

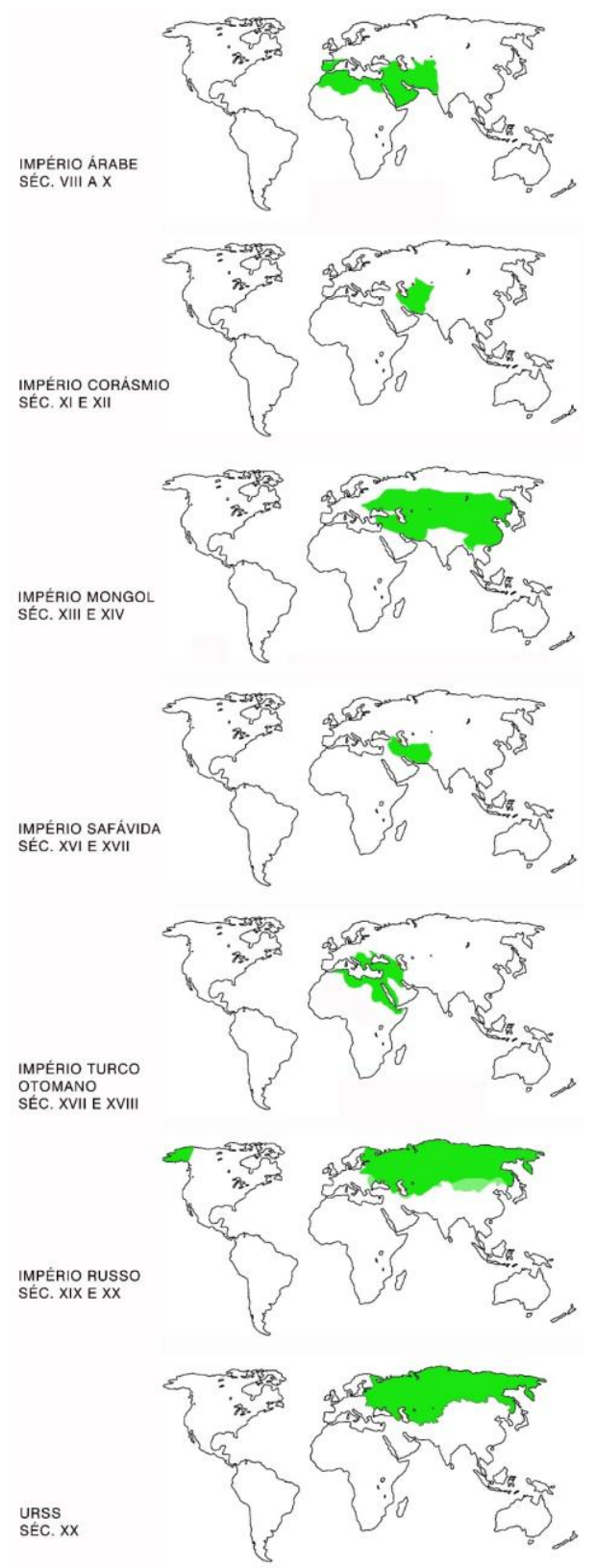

Fonte: Produzido pelos autores a partir das cartografias dos impérios, extraídas de Wikipedia e sobrepostas a mapa mundi disponível em Estados e Capitais do Brasil.com. 


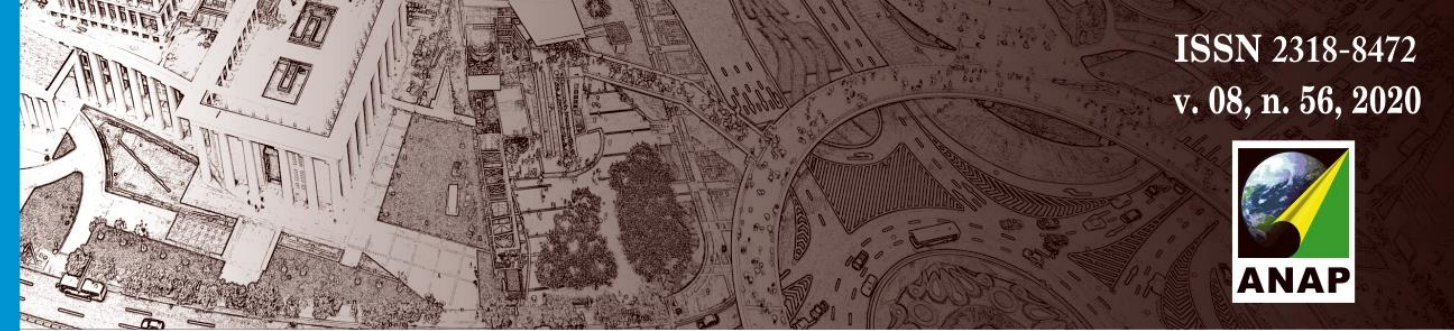

Revista Nacional de

Gerenciamento de Cidades

Vale lembrar que o século XX sedimentou a utilização do petróleo como matriz energética predominante, e sua produção acompanhou o desenvolvimento tecnológico de indústrias, máquinas e equipamentos como motores, navios e automóveis. Contudo, os anos que antecederam o fim da URSS foram de crise econômica e política, que implicou no sucateamento das instalações e plataformas, pela queda na extração de petróleo (WALL, 2010, p.170) e pela resistência do Azerbaijão ao regime soviético, com um período de retração econômica após o estabelecimento da independente República do Azerbaijão, acentuado pelas disputas de territórios com a Geórgia devido aos enclaves de minorias étnicas dentro dos dois países (CURTIS, 1995, p.91). No início da década de 1990, estas disputas trouxeram massacres e intervenções russas nas fronteiras nacionais.

O fim da URSS, em 1991, marca o início da existência do Azerbaijão enquanto Estado capaz de gerir recursos, promover políticas e atuar comercialmente como nação independente. Inicia-se um processo de desenvolvimento acelerado com base na indústria do petróleo e na abertura para a economia internacional. Este processo compõe um quadro de transformações ocorridas nos últimos quinze anos, que visaram promover as relações econômicas do país e atualizar o parque tecnológico e logístico para aumentar a extração e comercialização de petróleo e gás natural (WALL, 2010, p.171). Aliado a isso, observa-se a construção da imagem do Azerbaijão frente aos novos parceiros mundiais, baseada sobretudo na capital Baku.

\section{A CONDIÇÃO DO AZERBAIJÃO NO SÉCULO XXI E A TRANSFORMAÇÃO URBANA DE BAKU}

Após o desmonte do bloco soviético, as ações para reforma e recuperação do Azerbaijão incluíram medidas de reestruturação governamental e monetária, com ações para proporcionar a estabilização econômica e o desenvolvimento de setores diversos da economia, com especial atenção à exploração de petróleo e gás natural, alavancada pelo aporte de investimentos estrangeiros. $O$ estabelecimento das relações comerciais internacionais que impulsionam a atividade econômica colocou a cidade de Baku na função estratégica e representativa do novo papel desempenhado pelo Azerbaijão no cenário mundial.

Segundo Wall, (2010, p.171, 172), o país estava "livre para chamar a expertise ocidental pela primeira vez em duas gerações". As providências tomadas pelos governantes Abulfaz Elchibey e seu sucessor, Heidar Aliyev, incluíram estabelecer parcerias econômicas que introduzissem capital estrangeiro e tecnologia para alavancar a extração de petróleo e gás natural. Estabelecida uma abertura para a exploração dos campos de petróleo, nove empresas estrangeiras formaram um Consórcio: a Companhia de Operações Internacional do Azerbaijão -AIOC (WALL, 2010, p.172). Hoje, consorciadas à SOCAR (State Oil Company of Azerbaijan Republic ou Companhia Estatal do Petróleo da República do Azerbaijão), exploram petróleo e gás no Azerbaijão empresas dos Estados Unidos, Reino Unido, Japão, Turquia, Rússia, Itália, Arábia Saudita, 


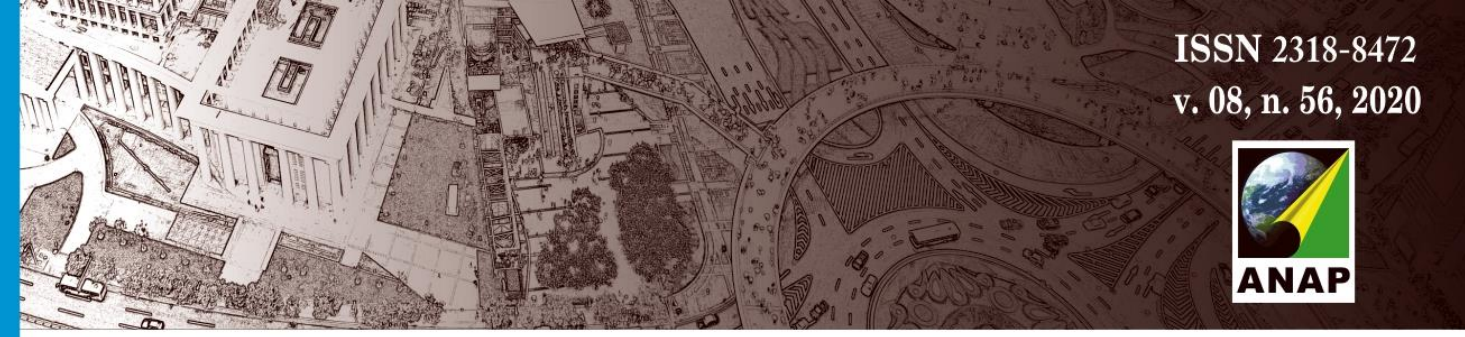

Revista Nacional de

Gerenciamento de Cidades

Noruega ${ }^{2}$. Investiu-se pesadamente nos campos de extração marítimos, o que ajuda a reverter a imagem da cidade de Baku, através da reconversão de antigas áreas industriais de extração em solo para trechos urbanizados da cidade global. Concomitantemente aos investimentos em extração, construíram-se oleodutos e gasodutos para escoar a produção, visando a saída para o mar Mediterrâneo e a conexão com a Europa. Podemos citar projetos transnacionais importantes, como o oleoduto entre Azerbaijão e Turquia (Baku-Tblisi-Ceilão, ou BTC), o segundo maior oleoduto do mundo, que conecta o Mar Cáspio ao Mar Negro e promove a saída do petróleo do Azerbaijão para mar (WALL, 2010, p.170). Além disso, uma sequência de gasodutos fará o percurso para transporte de gás natural, atualmente passando pela Georgia (Gasoduto Cáucaso Sul), em obras pela Turquia (Gasoduto Transanatoliano, com previsão de conclusão em 2018), com continuação até o sul da Itália, passando pela Grécia (Gasoduto Transadriático). Na outra ponta desta linha, a leste, um gasoduto sob o Mar Cáspio (Gasoduto Tanscaspiano) faz do Azerbaijão ponto de passagem no escoamento da produção de gás do Cazaquistão e do Turcomenistão em direção à Europa ${ }^{3}$.

Outras obras de infraestrutura acompanham as destinadas ao escoamento da produção de gás e petróleo. Podemos citar a conexão ferroviária do Azerbaijão com a Turquia, inaugurada em $2017^{4}$. Junto com a ferrovia, ocorreu investimento no transporte marítimo para conexão do Azerbaijão com os países da Ásia Central atravessando o Mar Cáspio, o que coloca o Azerbaijão como ponto importante na ligação entre Europa e Ásia. Soma-se a isso uma pesada modernização aeroportuária e obras de modernização das redes de comunicações e satélites. 0 desenvolvimento destes meios visa promover a circulação de mercadorias, pessoas e informações, ampliando a inserção do Azerbaijão na rede de relações internacionais para promoção de negócios e turismo 5 .

Também a cidade de Baku tem sofrido transformações que correspondem, em abrangência e escala, àquelas pelas quais passou o país. Ao fazer um histórico sobre os planos urbanísticos para Baku, Sandra Iseman (2012) explica que, com o crescimento acelerado em decorrência da exploração de petróleo no século XX, foram criados dois planos ordenadores ainda no período soviético, que resultaram em industrialização intensiva e extensas e monótonas áreas residenciais. Com a independência do país, na década de 1990, foram pensados um terceiro e quarto plano diretores para serem implementados nos anos 2000. Um grande plano urbanístico, que formulou a White City (Cidade Branca), foi lançado em 2010. Segundo a autora, estes novos

\footnotetext{
${ }^{2}$ Ao recolher informações no portal Wikipedia, encontramos dois consórcios importantes: Caspian International Petroleum Company e Azerbaijan International Operating Company. Disponível em:

https://en.wikipedia.org/wiki/Category:Oil_and_gas_companies_of_Azerbaijan, acesso em mai/2018.

3 Ver https://en.wikipedia.org/wiki/Trans-Anatolian_gas_pipeline,

https://en.wikipedia.org/wiki/South_Caucasus_Pipeline, https://en.wikipedia.org/wiki/Trans_Adriatic_Pipeline, https://en.wikipedia.org/wiki/Trans-Caspian_Gas_Pipeline.

${ }^{4}$ Ver https://www.railway-technology.com/projects/baku-tbilisi-kars/.

5 Diversas ações podem ser recolhidas da fala oficial do Azerbaijão no Portal do Fórum Econômico Mundial (2016, 2017). Ver https://www.weforum.org/agenda/2016/01/azerbaijan/;

https://www.weforum.org/agenda/2017/01/azerbaijans-economic-priorities-for-2017.
} 


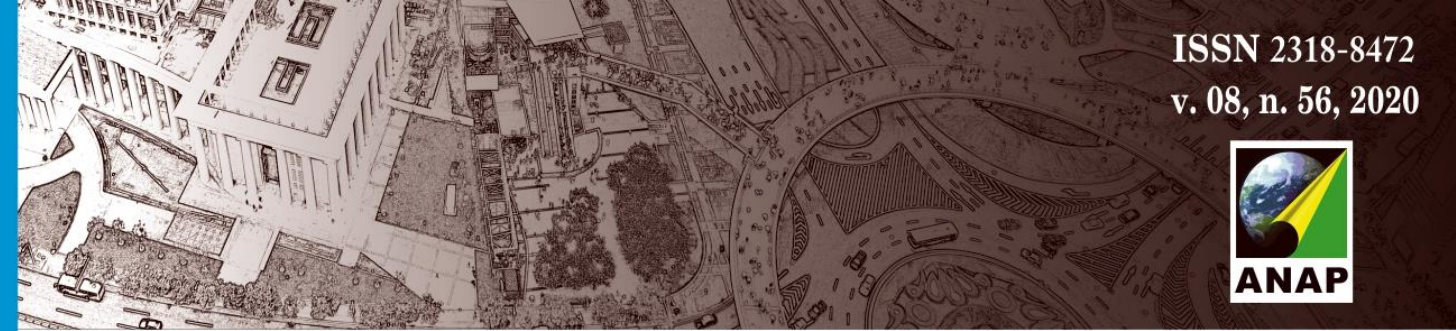

Revista Nacional de

Gerenciamento de Cidades

planos propõem novos modos de vida e novas dinâmicas urbanas, com uma atualização dos sistemas de transportes e do padrão das habitações e serviços.

Analisando as ações implementadas, é notório o desenvolvimento paralelo de diferentes transportes modais. Há investimento em sistema viário (estacionamentos subterrâneos e grandes vias estruturais), metroviário e de transporte marítimo. Acompanhando as obras estruturais, importantes espaços públicos da cidade também são transformados, bem como o parque edificado, que surge para abrigar hotéis, restaurantes, edifícios comerciais e centros financeiros, edifícios culturais e de lazer, além de prever habitações para além da atual população do Azerbaijão.

As vias e obras de infraestrutura auxiliam no entendimento geral da forma e funcionamento da cidade, na qual grandes porções do território têm sofrido alterações súbitas. Os arcos estruturadores que propomos para análise neste trabalho (o primeiro ao longo da orla do mar Cáspio e o segundo, internamente, ao longo da Avenida Heydar Aliyev e Winter Boulevard Bulevar de Inverno) são um modo de relacionar as obras de infraestrutura, os bairros em transformação e os projetos arquitetônicos. Cada arco de desenvolvimento contém setores ou polos de interesse. É importante ressaltar a característica peculiar de cada setor analisado, incluindo zonas históricas (a cidade árabe do século VIII e IX, o distrito de Sovetsky, que remonta ao século XIII), a recuperação de áreas industriais degradadas (White City), o aproveitamento do potencial paisagístico do Boulevard da Orla e a exploração do eixo de conexão entre o aeroporto e a estação ferroviária central (através da Avenida Heydar Aliyev e seus prolongamentos: o Winter Boulevard e o distrito de Sovetsky).

Além das transformações relacionadas aos negócios, vale lembrar os grandes eventos que a cidade tem sediado e aos quais tem se candidatado e que, além de projetá-la internacionalmente e atrair visitantes, contribuem para moldar a forma urbana e as relações entre infraestrutura, paisagem e arquitetura. Arenas, edifícios esportivos e de eventos pontuam a orla e se conectam às redes de transportes e espaços públicos. Somam-se a estes edifícios a implementação de edifícios culturais associados a uma arquitetura icônica, como o Museu do Tapete (arquiteto Franz Janz), o Centro Heydar Aliyev (Zaha Hadid), o Baku Cristal Hall (escritório GMP International), e a recuperação de inúmeros edifícios históricos (óperas e museus dos séculos XIX e XX, a cidade medieval, etc.), o que aumenta a atratividade, reforça a imageabilidade da cidade e associa bens culturais a objetos de consumo.

É importante mencionar ainda as transformações que ocorrem na escala cotidiana com alteração nos padrões de habitação, devido à grande quantidade de novos edifícios residenciais na cidade, em especial concentrados na White City, mas também nas ilhas Zira e Khaiser, que introduzem novas tipologias e arranjos nos edifícios de habitação. 


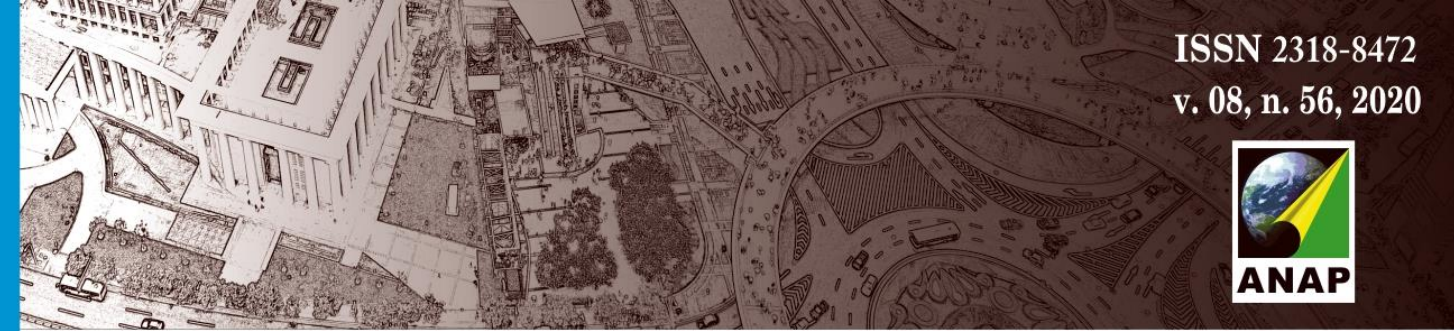

Revista Nacional de

Gerenciamento de Cidades

\section{CIDADE GLOBAL DO SÉCULO XXI}

Pode-se relacionar as transformações da cidade de Baku ao terceiro significado dado ao conceito de cidade global, segundo Carvalho (2000). Em seu texto, a autora discorre sobre as diferenças do conceito de cidade global, que deixou de ser um termo de origem analítica, decorrente do estado atingido por algumas metrópoles a partir de seu desenvolvimento histórico, e passou a ser um paradigma a ser alcançado pelas cidades com pretensões a inserir-se na economia globalizada, entendido como meta para a solução dos problemas urbanos, e que oculta ideologias e naturaliza as contradições da cidade contemporânea.

A autora menciona as primeiras utilizações do conceito de cidade global aplicadas por Sassen (1998), Levy (1997), e Marques e Torres (1997). Segundo a autora, naquele momento, o conceito equivaleria a um "diagnóstico" referente ao estado das metrópoles de primeiro mundo que, frente às novas tecnologias de comunicação e ao espraiamento do processo industrial mundial, passaram a concentrar o comando do sistema produtivo e os setores financeiro e terciário (CARVALHO, 2000, p.71). Este processo gerou novas dinâmicas sociais e espaciais no interior destas metrópoles, acentuando a diferença entre o trabalho qualificado e o trabalho não qualificado.

A autora ressalta que, no momento associado ao "diagnóstico", os elementos para a elaboração do conceito de cidade global são extraídos de processos históricos concretos. Em um segundo momento, que a autora situa temporalmente no final da década de 1990, surge um conceito ideal de cidade global que se descola do processo histórico, colocando-se como tipo. 0 tipo cidade ideal global, apresenta algumas características generalizantes: a cidade como ponto nodal entre a economia nacional e mundial; a concentração de serviços especializados de alta tecnologia; e novas desigualdades sociais (CARVALHO, 2000, p.72). A autora ressalta os problemas decorrentes da generalização do conceito de cidade global, cujas características passam a ser atributos sincrônicos comuns às cidades globais, em vez de considerar os processos históricos particulares que influíram nos fenômenos urbanos e aferir a real relação entre estas características de cidade global e o processo histórico particular de cada cidade.

Carvalho prossegue discorrendo sobre a transformação do conceito de cidade global, quando este passou de ideal (ou tipo) a paradigma. Neste caso, o conceito afirma-se como aporte teórico contemporâneo, e as características da cidade global enquanto tipo passam a ser almejadas e ranqueadas, naturalizando-se as contradições do processo global, e ocultando-se o aspecto ideológico presente nesta operação.

Arantes afirma que a condução técnica do urbanismo, a serviço da cidade global, passa a instrumento das forças produtivas da cidade segundo esta lógica, adotando-se, na "terceira era do urbanismo", o planejamento estratégico. Esta linha pressupõe uma abordagem da cidade enquanto mercadoria, e o novo planejamento, hierarquizador e intensivo, busca adequar a cidade à nova fase do capitalismo financeiro e terciário, com "atenção voltada para as áreas intersticiais, vazias ou degradadas, no sentido de promover o adensamento urbano, porém 


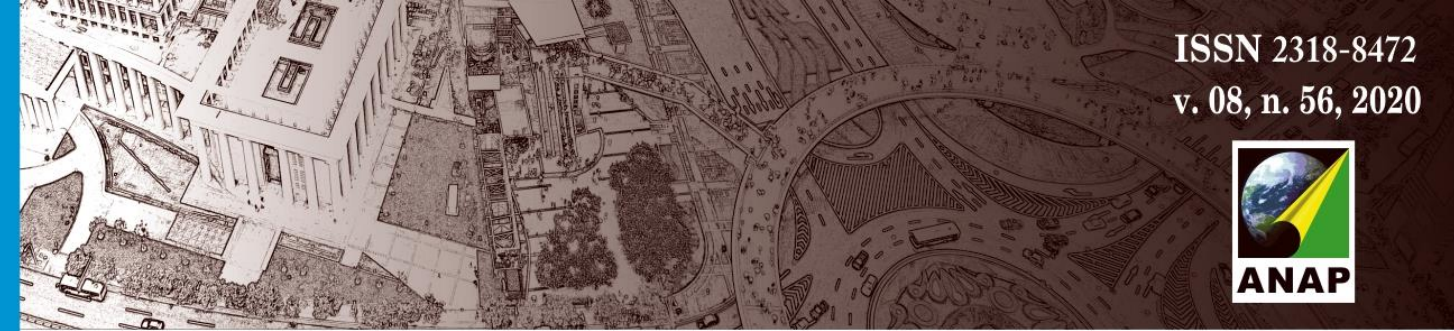

Revista Nacional de

Gerenciamento de Cidades

requalificando-as, seja do ponto de vista do uso, seja dos atributos ambientais" (ARANTES, 2019, p.18), mas gerando o que a autora chama de "arrastão empresarial" provocado pelo mercado (ARANTES, 2019, p.20). Ainda segundo Arantes, os elementos da cultura e da arquitetura local passam a ser assimilados pelo capital, gerando o que a autora denomina "culturalismo de mercado" (ARANTES, 2019, P.16).

O planejamento estratégico é capaz de articular as ações públicas e privadas para coordená-las no processo de produção da cidade com base no capital global, ao mesmo tempo em que subjuga as peculiaridades da cidade, que consistem nos valores culturais e históricos, para que trabalhem em prol das mesmas forças dominantes. Conforme a autora, tanto os procedimentos racionalistas do movimento moderno, como a revisão pós-moderna que aportou valores ao processo de urbanização, foram incorporadas ao processo de transformação das cidades globais, e ambos são identificados nas recentes transformações da cidade de Baku.

\section{ANÁLISE DOS SETORES URBANOS COMPONDO EIXOS DE TRANSFORMAÇÃO URBANA}

A partir de visita a Baku e de informações recolhidas em sites de arquitetura e sites institucionais da cidade de Baku, as obras de Baku a partir de meados da década de 1990 foram recolhidas, selecionadas e mapeadas. $\mathrm{O}$ mapeamento possibilitou identificar setores que concentram as obras, articulados entre si definindo arcos ou eixos de transformação urbana. A identificação dos vetores, compostos eixos infraestruturais e por setores urbanos diferenciados, foi objetivo desta parte do trabalho, em que se buscou conferir um sentido às ações promovidas no território nos últimos quinze anos.

Para recolher as obras e compreender as transformações da cidade, tomou-se por base uma leitura empírica da cidade, visitada em janeiro de 2017. Para mapeamento e localização das obras, a pesquisa utilizou-se também de cartas e fotos aéreas, além de sites oficiais e não oficiais de divulgação dos projetos em andamento, finalizados e futuros.

Os setores identificados apresentam um critério de delimitação moldado de modo variável para melhor atender a nossos propósitos. Assim, o setor pode ser considerado todo um bairro, uma avenida, a orla que atravessa a cidade, ou ainda um conjunto de edifícios. Podem também incluir situações urbanas consolidadas ou edifícios pré-existentes que passam a cumprir um novo papel a partir do agenciamento proposto para o território.

Foram considerados dois grandes arcos ou vetores de transformação: o primeiro, de maior visibilidade, ao longo da orla do Mar Cáspio (Figura 3); o segundo corta a cidade internamente, interligando a região do aeroporto até a Universidade do Azerbaijão, e atravessando porções urbanas que sofreram grandes transformações (Figura 10).

Segue uma descrição geral de cada um dos vetores, com a caracterização dos setores que o compõem. 



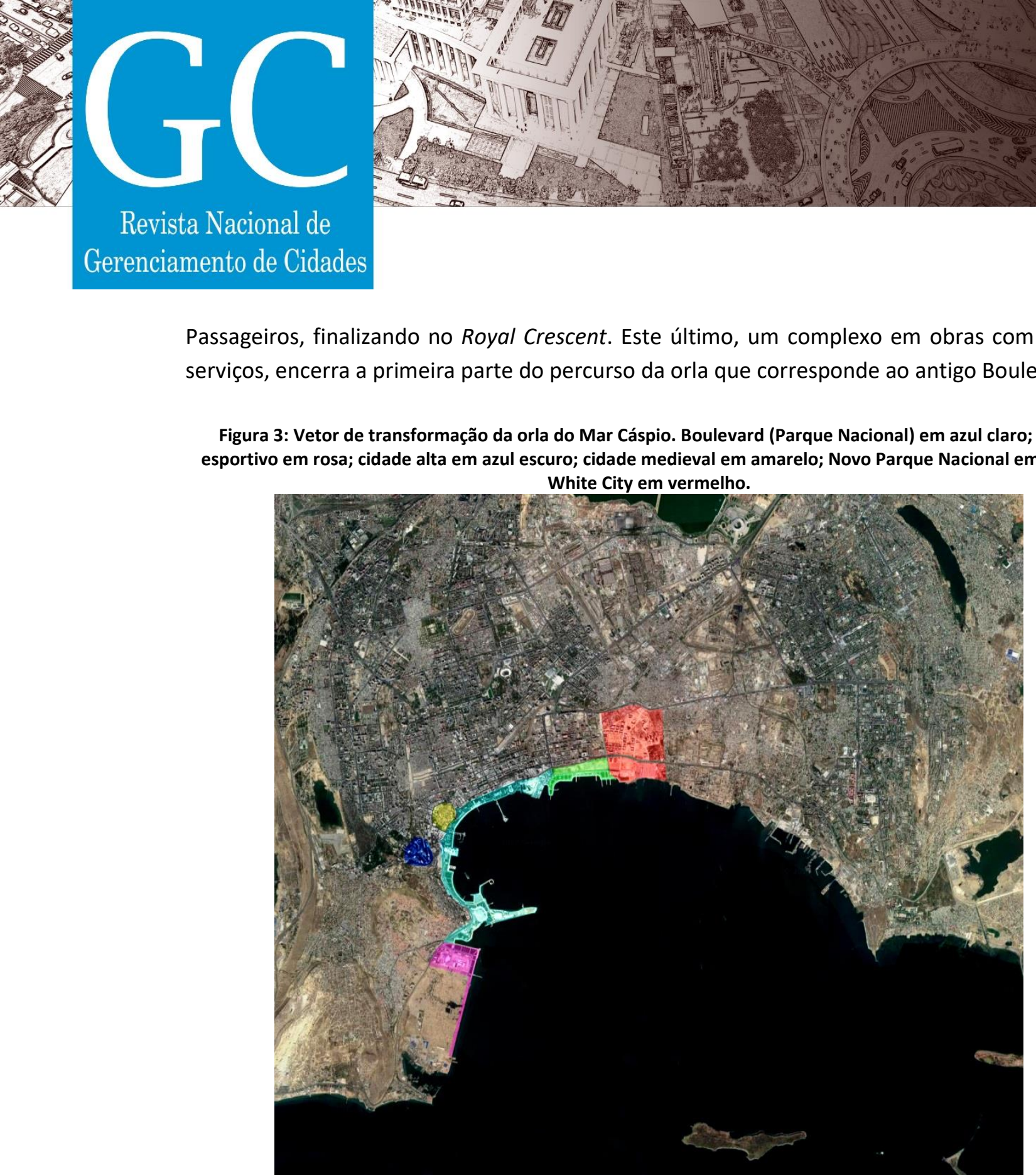

Passageiros, finalizando no Royal Crescent. Este último, um complexo em obras com hotel e serviços, encerra a primeira parte do percurso da orla que corresponde ao antigo Boulevard.

Figura 3: Vetor de transformação da orla do Mar Cáspio. Boulevard (Parque Nacional) em azul claro; setor esportivo em rosa; cidade alta em azul escuro; cidade medieval em amarelo; Novo Parque Nacional em verde;

Fonte: Produzido pelos autores a partir de Google Maps.

Figura 4. Vista da orla de Baku a partir do Upland Park. À esquerda, as Flame Towers.

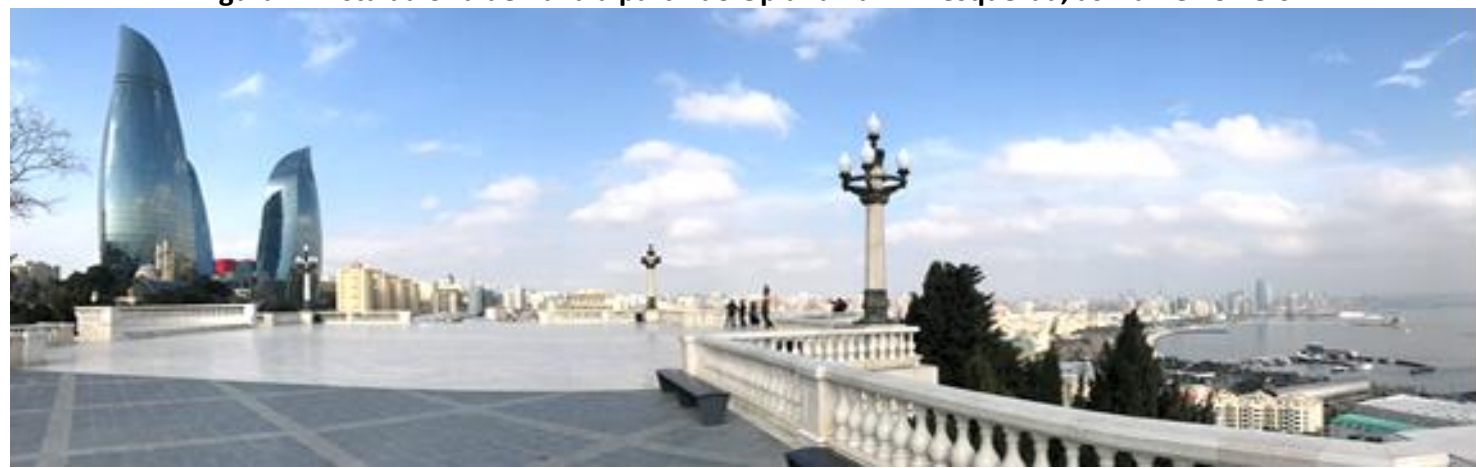

Fonte: Foto dos autores, 2017. 



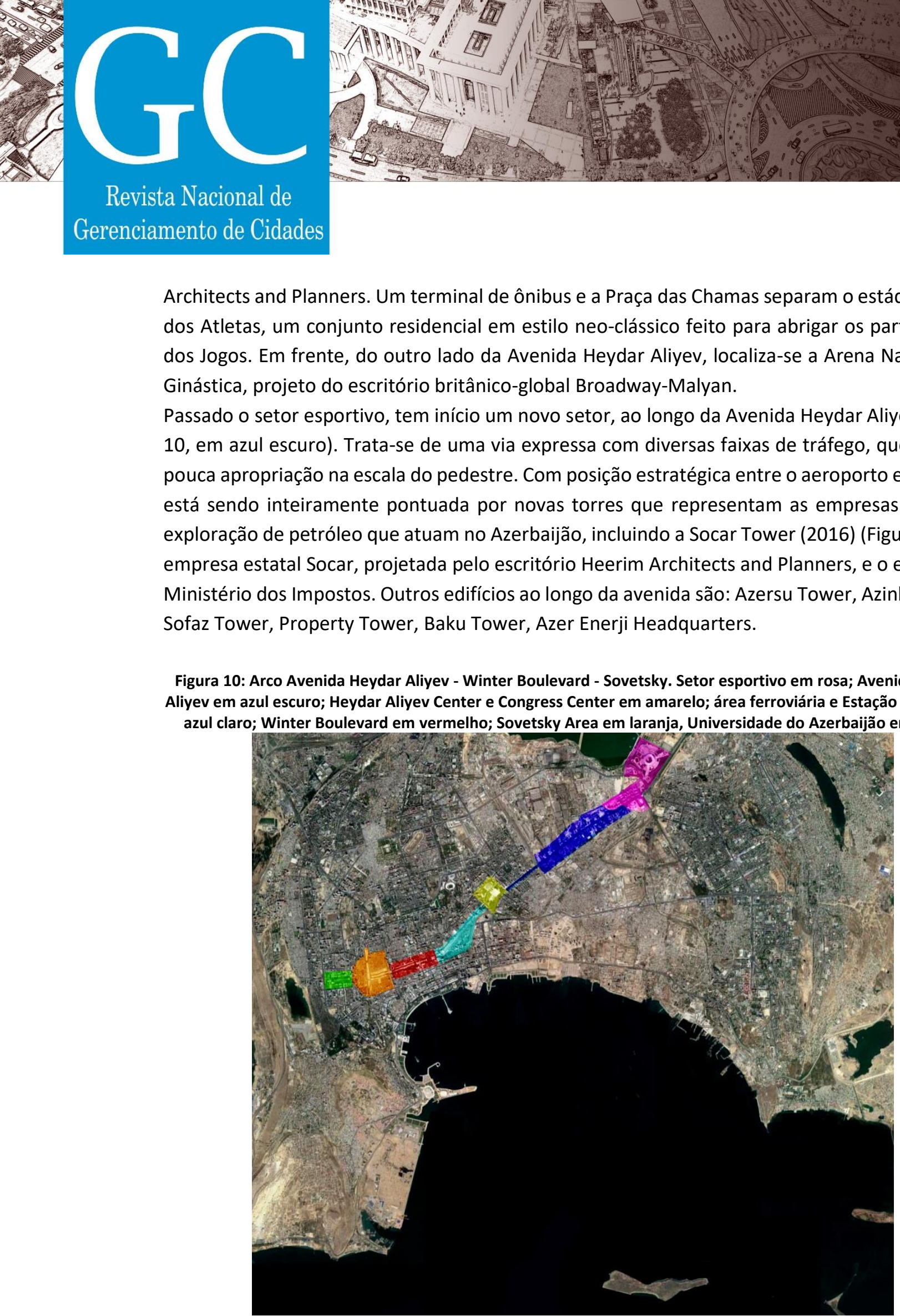

Architects and Planners. Um terminal de ônibus e a Praça das Chamas separam o estádio da Vila dos Atletas, um conjunto residencial em estilo neo-clássico feito para abrigar os participantes dos Jogos. Em frente, do outro lado da Avenida Heydar Aliyev, localiza-se a Arena Nacional de Ginástica, projeto do escritório britânico-global Broadway-Malyan.

Passado o setor esportivo, tem início um novo setor, ao longo da Avenida Heydar Aliyev (Figura orto e a cidade, exploração de petróleo que atuam no Azerbaijão, incluindo a Socar Tower (2016) (Figura 12), da empresa estatal Socar, projetada pelo escritório Heerim Architects and Planners, e o edifício do Ministério dos Impostos. Outros edifícios ao longo da avenida são: Azersu Tower, Azinko Tower, Sofaz Tower, Property Tower, Baku Tower, Azer Enerji Headquarters.

Figura 10: Arco Avenida Heydar Aliyev - Winter Boulevard - Sovetsky. Setor esportivo em rosa; Avenida Heydar Aliyev em azul escuro; Heydar Aliyev Center e Congress Center em amarelo; área ferroviária e Estação Central em

Fonte: Produzido pelos autores a partir de Google Maps. 



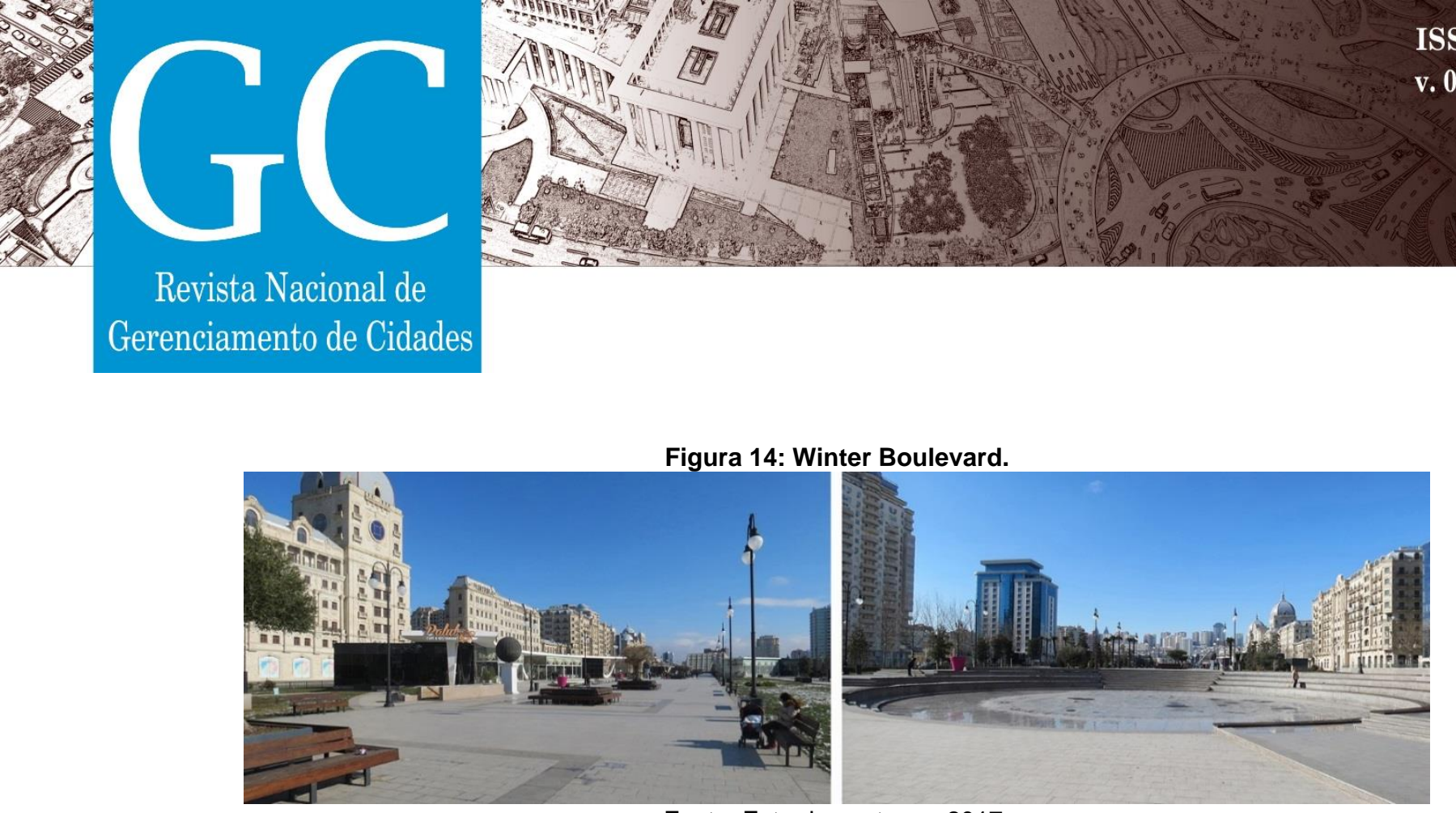

Fonte: Foto dos autores, 2017.

Figura 15: Demolição no Distrito de Sovetsky.

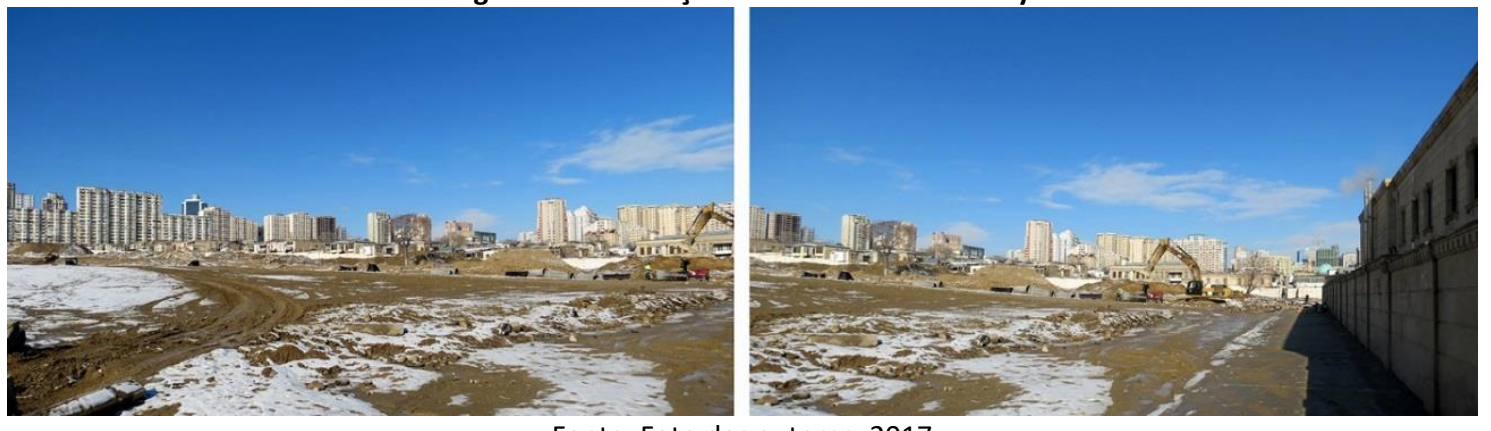

Fonte: Foto dos autores, 2017.

\section{CONSIDERAÇÕES}

Após a autonomia política do Azerbaijão com a dissolução da antiga União Soviética, a capital Baku tem sofrido transformações que refletem na escala urbana a o papel que o país assumiu perante a economia global. Este artigo circunstanciou as transformações urbanas em um panorama histórico e identificou conceitos que permitem associar as recentes transformações de Baku ao entendimento de cidade global como paradigma (CARVALHO, 2000), em que determinadas características das cidades globais são buscadas através do planejamento estratégico.

Além disso, esta pesquisa traz uma leitura da cidade a partir do mapeamento de obras recentes associadas a eixos de transformação da cidade, sinalizando para a relação entre o planejamento geral da cidade, a partir da ação do estado, e a participação do mercado. O conjunto de obras ilustra, de modo exemplar em Baku, o tipo de ação tomada pelas cidades com pretensões a cidade global, que inclui aportes na infraestrutura, a construção de edifícios icônicos, sediar jogos e eventos e promover sobretudo os negócios. As intervenções levantadas, sejam na forma de edifícios isolados, espaços públicos e viários, ou bairros inteiros, vêm acompanhadas por obras de impacto nas redes de infraestrutura urbana, melhoria das comunicações, transportes e serviços, compreendidos tanto na escala local como enquanto instrumentos de facilitação das relações globais. Para além da especificidade histórica que deflagra as transformações urbanas em Baku, é importante ressaltar que tais transformações correspondem, em grande medida, às 


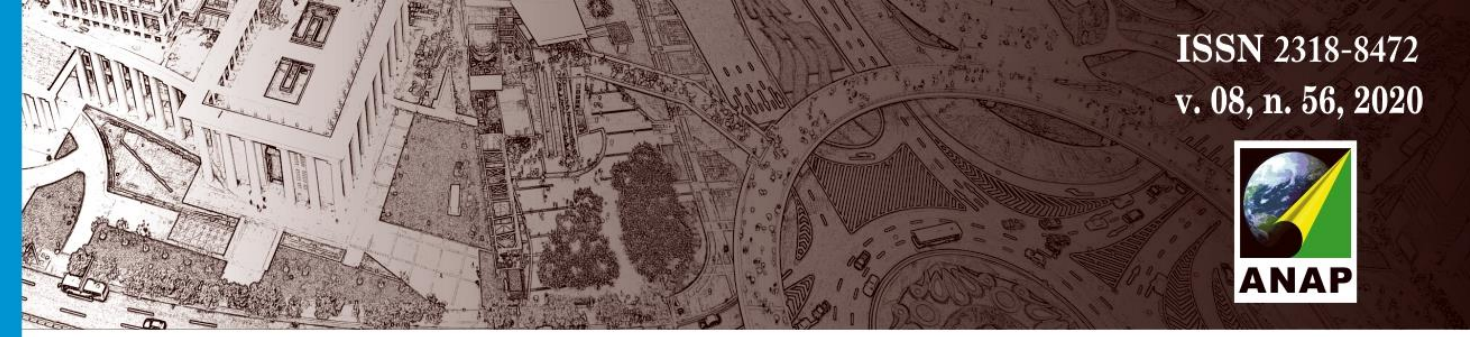

\section{Revista Nacional de}

Gerenciamento de Cidades

ações adotadas por cidades com pretensões globais, o que faz de Baku um caso exemplar devido à concentração de tais ações em curto espaço de tempo.

Outra consideração a ser feita refere-se ao fato de que as transformações em Baku afetam simultaneamente duas escalas: o âmbito local, relacionado à destruição de bairros antigos e implantação de novos bairros residenciais com padrão mercadológico de habitação (vide os edifícios parisienses em White City), e também a escala global, ao facilitar o acesso e circulação dos visitantes a negócios, turismo ou eventos internacionais. Algumas das mutações nas áreas urbanas incentivaram a reconversão de partes degradadas, como em White City; outras, contudo, destruíram vizinhanças consolidadas para submeter o espaço urbano à lógica da cidade global, como no Distrito de Sovetsky. A identidade e memória da cidade e do povo azeri contrasta com novas dinâmicas, novos fluxos migratórios e novos modos de vida. Os levantamentos revelaram que, enquanto muitos monumentos são preservados, como edifícios centenários importantes que foram recentemente recuperados, a arquitetura comum, diretamente ligada à vida das pessoas, é substituída por uma arquitetura homogênea, universal, dos negócios, feita em sua maioria por escritórios de arquitetura estrangeiros.

De todo modo, fica clara a opção do país pela modernização de sua capital e, em paralelo, a tentativa de construir um espaço de identidade que converge a história remota com a história recente, assumindo como identidade a própria condição de cidade global contemporânea.

\section{REFERÊNCIAS BIBLIOGRÁFICAS}

ARANTES, O. B. F. Uma estratégia fatal. A cultura nas novas gestões urbanas. In: ARANTES, O.; VAINER, C.; MARICATO, E. A cidade do pensamento único. Desmanchando consensos. Petrópolis, Editora Vozes, 2019.

CARVALHO, M. Cidade Global. Anotações críticas sobre um conceito. São Paulo em perspectiva. São Paulo, v.14, n.4, 2000.

CURTIS, G. E. Armenia, Azerbaijan and Georgia: country studies. S.I., Federal Research Division, Library of Congress, 1995.

GAUSA, M. et al. Dicionario metápolis de arquitectura avanzada: Ciudad y tecnologia em la sociedade de la infromación. Barcelona, Actar, [ca. 2000].

ISEMAN, S. Baku, Azerbaijan: A Case for a Master Plan. [S.I.]: [s.n.], 2012. Disponível em:

https://sandraiseman.wordpress.com/2012/06/18/baku-azerbaijan-a-case-for-a-master-plan-4-2/.

SOLÀ-MORALES, I. Territórios. Barcelona, Gustavo Gili, 2002.

WAAL, T. The Caucasus. An introduction. New York, Oxford University Press, 2010. 